\title{
The Impact of Body Mass Index on Assisted Reproductive Treatments
}

\author{
Prasanna Raj Supramaniam ${ }^{1 *}$, Monica Mittal², Lee Nai Lim² \\ ${ }^{1}$ Department of Women and Children, Milton Keynes University Hospital, Milton Keynes, UK \\ ${ }^{2}$ Department of Women and Children, Oxford University Hospitals NHS Foundation Trust, Oxford, UK \\ Email: *prasannaraj@doctors.org.uk
}

How to cite this paper: Supramaniam, P.R., Mittal, M. and Lim, L.N. (2017) The Impact of Body Mass Index on Assisted Reproductive Treatments. Open Journal of Obstetrics and Gynecology, 7, 562-570. https://doi.org/10.4236/ojog.2017.75059

Received: April 3, 2017

Accepted: May 23, 2017

Published: May 26, 2017

Copyright ( 92017 by authors and Scientific Research Publishing Inc. This work is licensed under the Creative Commons Attribution International License (CC BY 4.0).

http://creativecommons.org/licenses/by/4.0/

cC) (i) Open Access

\begin{abstract}
Multiparity amongst women with a body mass index (BMI) $\geq 30 \mathrm{Kg} / \mathrm{m}^{2}$ is a common occurrence despite there being a known clear association with a decline in fecundity in women who are overweight or obese. These women, also pose further concerns, as they are at increased risk of antenatal complications such as preeclampsia and gestational diabetes. Over the years, a number of different modalities of fertility treatments have been tried and tested in this cohort of women to find the optimal treatment to improve their reproductive capacity. There has been an exponential increase in knowledge and understanding towards managing patients with a raised BMI, particularly through assisted reproductive treatments. Although the efficacies of various forms of fertility treatments have been shown to be affected by a rise in BMI, there is yet to be a definitive understanding as to the optimal management of these patients. The literature supports weight loss alone as an effective intervention in improving the reproductive capacity of women with a raised BMI with unexplained infertility. Furthermore, if live birth rate is taken as the desired outcome measure, then ovarian drilling and in vitro fertilisation (IVF) treatment have been shown to yield the best results in overweight and obese patients when comparisons are drawn to other interventions such as natural conception and treatment with clomiphene citrate.
\end{abstract}

\section{Keywords}

Assisted Reproductive Treatments, Body Mass Index, Live Birth Rate, Overweight, Obesity

\section{Introduction}

Obesity is a common challenge for today's society, with a large burden placed on the healthcare system. Clinicians on all fronts face an uphill task in managing 
and treating patients with obesity. It has not only changed the outlook of medicine, but also poses new questions about diseases and the current method of managing them.

Obesity in adult women in the UK, accounts for $26.1 \%$ of the population, with an overall increase seen in the past two decades (16.4\%) [1].

The World Health Organisation (WHO) classification of Body Mass Index (BMI) defines a BMI of $18.5-24.9 \mathrm{Kg} / \mathrm{m}^{2}$ as normal, overweight as a BMI of 25 $29.9 \mathrm{Kg} / \mathrm{m}^{2}$ and obese as a $\mathrm{BMI} \geq 30 \mathrm{Kg} / \mathrm{m}^{2}$. In the obese category, this is further subdivided into Class $1\left(30.0-34.9 \mathrm{Kg} / \mathrm{m}^{2}\right)$, Class $2\left(35.0-39.9 \mathrm{Kg} / \mathrm{m}^{2}\right)$ and Class $3\left(\geq 40.0 \mathrm{Kg} / \mathrm{m}^{2}\right)$.

Women with a raised BMI are known to have impaired fecundity, supported by good quality evidence which has shown that modifications in lifestyle can help to restore their fertility [2]. Despite this, a significant portion of the population presenting to an infertility clinic have been found to have a raised BMI. The difficulties encountered by the treating clinician are that no one method of intervention has been shown to be superior in managing these patients over another; there is a fine balance between achieving the desired response and the complications associated with the proposed procedures. This is further compounded by obese women being at greater risk of obstetric complications [3].

One of the major drives in improving outcomes in women receiving fertility treatments has been to limit the BMI eligibility criteria. Although some may see this as a harsh reality, it is a necessary benchmark to prevent further complications to patients who fall into this cohort of raised BMI. Nevertheless, patients are not encouraged to lose weight whilst pregnant, irrespective of their BMI category, instead, most healthcare providers have now developed services to promote weight maintenance throughout pregnancy. The aim is to limit exponential weight gain, which women, particularly in these BMI categories experience. A quantifiable clinical marker validating the weight holding programmes in overweight and obese patients, is blood sugar, whereby improved control has been seen without the need for additional medication in patients following these programmes.

This review aims to establish the effect of BMI on assisted reproductive treatments, looking at the current literature to help establish the optimal treatment options for overweight and obese patients to improve their reproductive outcomes.

\section{Materials and Methods}

Literature searches were conducted through the Cochrane Library, Medline, Embase and NHS Evidence, for articles between (1966-2017), using the medical subject headings (MeSH) and text words: Body Mass Index (BMI), overweight, obesity, natural conception, clomid, clomiphene citrate, ovarian drilling, follicle stimulating hormone (FSH), gonadotrophins, ovulation induction, in vitro fertilisation (IVF) and intracytoplasmic sperm injection (ICSI). The searches were conducted using five separate subheadings: 1) BMI and natural conception; 2) 
BMI and ovarian drilling; 3) BMI and ovulation induction; 4) BMI and clomiphene citrate; and, 5) BMI and IVF/ICSI.

\section{Results}

\subsection{BMI and Natural Conception}

Women with a normal BMI have been shown to have a three-fold greater fertility capacity than obese women [4], with a rise in the spontaneous conception rate seen in women with documented weight loss [5]. Women with a BMI $>32$ $\mathrm{Kg} / \mathrm{m}^{2}$ have been shown to have a significantly lower live birth rate compared to women with a $\mathrm{BMI}<32 \mathrm{Kg} / \mathrm{m}^{2}$ [6]. Overweight or obese women are more likely to suffer from oligomenorrhoea. They have also been shown to have a higher risk of miscarriage than the background population; a miscarriage rate of $13.7 \%$ has been documented in obese women, compared to $10.9 \%$ in women with a normal BMI [7]. The recurrent miscarriage rate has also been speculated to be increased in obese women, however, a recent systematic review has not confirmed this [7].

\subsection{BMI and Ovarian Drilling}

Ovarian drilling is commonly performed laparoscopically. The risks associated with surgery, from the anaesthetic to the surgical procedure increase in larger patients. The theoretical physiological benefit is reduced in women with a BMI $\geq$ $35 \mathrm{Kg} / \mathrm{m}^{2}$ and a raised serum testosterone level [8].

\subsection{BMI and Ovulation Induction}

BMI has been shown to be inversely proportional to the number of follicles produced and directly proportional to the gonadotrophin dosage administered. Obese patients have been found to have a lower follicular count, but with no demonstrable impact on the clinical pregnancy and spontaneous miscarriage rate across all BMI categories [9].

Women with a higher BMI have been shown to require higher dosages and a longer duration of stimulation when treated with gonadotrophins for ovulation induction [10]. However, no difference in the recorded live birth rate has been seen in women up to the age of 40 years with a BMI of up to $34 \mathrm{Kg} / \mathrm{m}^{2}$. In contrast, another study looking at women under the age of 38 years demonstrated that morbidly obese women with a BMI $\geq 40 \mathrm{Kg} / \mathrm{m}^{2}$ had a statistically significant reduction in pregnancy rates when compared to women with a normal BMI (30.5\% versus $41.7 \%$; $\mathrm{p}<0.05)$ [11].

\subsection{BMI, Clomiphene Citrate and Metformin Therapy}

Obese women have been shown to have a lower clinical pregnancy rate and birth rate with clomiphene citrate [6]. However, clomiphene citrate has also been shown to be superior at inducing ovulation in women with a BMI $>30 \mathrm{Kg} / \mathrm{m}^{2}$ when compared with metformin [12]. Metformin has been shown to have better efficacy in patients who demonstrate insulin resistant polycystic ovarian syn- 
drome (PCOS) [13].

\subsection{BMI and IVF/ICSI}

The impact of BMI on assisted reproductive treatments (ART), such as IVF and ICSI is conflicting, with some studies showing no effect [14], and others demonstrating a poor pregnancy outcome with a higher BMI. Two large meta-analyses looking at the impact of BMI on IVF outcomes found insufficient evidence to draw firm conclusions on the impact of BMI on live birth rate [15] [16]. However, another meta-analysis addressing the same question, revealed a statically significant difference across all BMI categories on live birth rates [17]; women with a BMI of $\geq 25 \mathrm{Kg} / \mathrm{m}^{2}$ who underwent an IVF/ICSI cycle had a statistically significant lower live birth rate when compared to women who underwent the same procedure with a BMI of $<25 \mathrm{Kg} / \mathrm{m}^{2}$ (relative risk [RR] 0.84, 95\% confidence interval $[\mathrm{Cl}] 0.77-0.92, \mathrm{p}<0.05)$. In addition, women with a raised BMI were shown to require a significantly higher gonadotrophin dosage and a longer duration of stimulation to achieve the desired result; women with a BMI $<25$ $\mathrm{Kg} / \mathrm{m}^{2}$ were shown to require a significantly shorter duration of stimulation compared to women with a $\mathrm{BMI} \geq 25 \mathrm{Kg} / \mathrm{m}^{2}$ (weighted mean difference [WMD] $0.88,95 \% \mathrm{Cl} 0.49-1.27, \mathrm{p}<0.05$ ) [17] [18]. Furthermore, the difference in gonadotrophin dosage requirements for controlled ovarian stimulation becomes more prominent in women with a $\mathrm{BMI} \geq 30 \mathrm{Kg} / \mathrm{m}^{2}$ (WMD 406.77, 95\% CI 169.26 - 644.2, p < 0.05) [19] [20] [21] [22] [23].

In addtion, differences in controlled ovarian superovulation in IVF and ICSI cycles has been demonstrated across the BMI subcategories when different dosages of human chorionic gonadotrophin (hCG) is administered. A significant reduction in the serum hCG level has been demonstrated as the BMI increases. Furthermore, the clinical pregnancy and live birth rate have been demonstrated to be significantly lower in patients with a $\mathrm{BMI}<25 \mathrm{Kg} / \mathrm{m}^{2}$, as well as in women with a BMI $>30 \mathrm{Kg} / \mathrm{m}^{2}$ when 5000 International Units (IU) of hCG is administered, compared to patients with a BMI between $25-30 \mathrm{Kg} / \mathrm{m}^{2}(\mathrm{p}<0.05)$ [24]. In contrast, a study by Kavrut et al. (2013) [25], did not show a significant statistical difference in the clinical pregnancy rate in women with a BMI $\geq 30 \mathrm{Kg} / \mathrm{m}^{2}$ when a higher dose of recombinant hCG (250 micrograms versus 500 micrograms) was administered.

Ovarian hyperstimulation syndrome (OHSS) is a serious complication of ART. A prospective cohort study looking at the administration of recombinant follicle stimulating hormone (FSH) and a gonadotrophin releasing hormone (GnRH) antagonist in two different groups of patients, (both of whom were diagnosed with PCOS), with a BMI of $<29 \mathrm{Kg} / \mathrm{m}^{2}$ or a BMI $>29 \mathrm{Kg} / \mathrm{m}^{2}$, demonstrated a higher occurrence of OHSS in the group with a BMI $>29 \mathrm{Kg} / \mathrm{m}^{2}(\mathrm{p}<$ 0.05). Furthermore, a higher dose of recombinant FSH, 200IU in patients with a BMI $>29 \mathrm{Kg} / \mathrm{m}^{2}$ compared to $100 \mathrm{IU}$ in patients with a BMI $<29 \mathrm{Kg} / \mathrm{m}^{2}$, was not found to be associated with a higher pregnancy rate per oocyte retrieval ( $\mathrm{p}<$ 0.05) [26]. In contrast, other studies have stated that the risk of developing 
OHSS is inversely proportional to the BMI; one study showed $19.6 \%$ of women with a normal to low BMI developed OHSS, compared to $3.2 \%$ in the obese category [27].

Other studies, comparing the impact of a $\mathrm{GnRH}$ agonist versus an antagonist treatment cycle in different BMI categories, has shown a significantly higher pregnancy rate in $\mathrm{GnRH}$ agonist protocols in women with a $\mathrm{BMI}<25 \mathrm{Kg} / \mathrm{m}^{2}$, and no difference in women with a BMI $>25 \mathrm{Kg} / \mathrm{m}^{2}$ [28].

Furthermore, women with a BMI $>40 \mathrm{Kg} / \mathrm{m}^{2}$ undergoing IVF treatment are at an increased risk of pre-term labour and delivery of a large for gestational age baby compared to women of a normal BMI [11].

\section{Discussion}

A normal BMI can increase a woman's reproductive potential by three-fold [4], with evidence showing a higher spontaneous conception rate in women with documented weight loss and a reduction in their antenatal, intrapartum and postpartum risk score assessment [5]. Obese patients have been shown to have a lower pregnancy rate, a higher early pregnancy loss rate and a lower overall live birth rate [29].

Obesity is known to have an impact on the hypothalamic-pituitary ovarian axis, and on oocyte, embryo and endometrial development, including implantation [30], with larger women being shown to have a higher miscarriage rate compared to woman with a normal BMI [7]. PCOS is more common in obese patients. The cause and effect of PCOS towards obesity is clearly documented in endocrinology journals, however, it cannot be assumed that patients with PCOS will always be obese. There is a fine crossover amongst articles whilst describing obesity and ART when they address PCOS as a causative factor. Overweight or obese women are more likely to suffer from oligomenorrhoea and anovulation, impacting fertility.

Poor reproductive outcomes are associated with chromosomal alignment anomalies and disarrayed meiotic spindle formation. A study has shown that severely obese women have a significantly higher percentage of disarrayed meiotic spindles when compared to women with a normal BMI (58.9\% versus $35.1 \%$; odds ratio [OR] 2.68, 95\% CI 1.39 - 5.15, p < 0.05) [31]. This data should be interpreted with caution due to the small sample size and inclusion of only failed fertilized oocytes.

Laparoscopic ovarian drilling is a treatment option discussed with anovulatory patients wishing to conceive. Menstrual cycles and endocrine profiles have been restored in women undergoing ovulation induction surgery [32], including the blood flow within the ovarian stroma [33]. Ovulation and pregnancy rates are comparable between ovarian drilling and treatment with exogenous gonadotrophin [34]. The procedure itself is associated with minimal morbidity and mortality. However, with the average BMI of the background population steadily increasing, this has brought with it technical challenges. A study has shown that five small punctures to the ovary, instead of ten, is sufficient to produce the de- 
sired results in these women; alleviating their hyperandrogenic state as well as improving their reproductive outcome [35]. However, obese women and those with a raised serum testosterone level have seen less benefit from this treatment, with obesity being a risk factor for resistance towards ovarian surgery [8].

A new challenge facing clinicians in the management of obese women is dose titration. The data is conflicting with some studies showing differences in outcome based on drug dosages across the BMI categories and others not. Overall, BMI has been shown to be inversely proportional to the number of follicles produced and directly proportional to the gonadotrophin dosage required [23] and duration of stimulation [17]. A large meta-analysis by Rittenberg et al. (2011) [17] has shown an overall statistically significant lower live birth rate in IVF/ICSI cycles in women with a $\mathrm{BMI} \geq 25 \mathrm{Kg} / \mathrm{m}^{2}$ compared to women who underwent the same procedure with a normal BMI. In contrast, the risk of OHSS is inversely proportional to the BMI of the woman [28].

In addition, obese patients have an increased obstetric morbidity and mortality rate (CMACE 2010). This is further compounded with IVF treatment, whereby women with a BMI $>40 \mathrm{Kg} / \mathrm{m}^{2}$ have been shown to be at increased risk of pre-term labour and of having a large for gestational age baby [11].

\section{Conclusions}

A good body of evidence exists, documenting the impact of BMI on the female reproductive system, and particularly on the available fertility treatments. Multiple studies have concluded that a high BMI is associated with a reduced natural conception live birth rate. Weight loss alone has been proven to be an effective intervention in improving the reproductive capacity of women with a raised BMI with unexplained infertility. Furthermore, obese patients have been found to be at increased risk of antenatal complications such as pre-eclampsia and gestational diabetes [36].

Several factors have been identified to impact the success of an ART cycle. The quality of the embryo is commonly implicated and is thought to be inversely proportional to the weight of the woman. This may explain one mechanism by which the early pregnancy loss rate is seen to be higher in this cohort of patients. Interestingly, the evidence regarding the impact of a raised BMI on the endometrium is inconsistent. Some have documented a more receptive endometrium with an increase in BMI, whilst others report a hostile endometrium in higher BMI categories.

Ovulation induction as an ART modality is well described in the literature. A number of good quality studies have looked at developing the optimal treatment protocol for overweight or obese patients. Although a slightly longer duration of treatment and in some cases a higher dosage of medication is required, the live birth rate in overweight and obese women is comparable to women of a normal BMI category [37].

The results from studies looking at the impact of BMI on IVF outcomes have been conflicting. Some authors have demonstrated a favourable influence of BMI 
on IVF outcomes, whilst others have reported an inversely proportional live birth rate with IVF treatment and a rising BMI. A recent meta-analysis performed in 2011 by Rittenberg et al. [17], supports the latter theory of a reduced live birth rate in overweight and obese women when compared to women with a normal BMI.

Overall, the live birth rate is lower in overweight and obese women when compared to an age matched control of a normal BMI. No single defined intervention has been identified to best manage overweight or obese women. Advancements in infertility treatments for this cohort of patients brings with it other difficulties and considerations for the ongoing management of these women in the obstetric period, for both obstetricians and anaesthesiologists.

\section{References}

[1] NHS Information Centre for Health and Social Care (2012) Statistics on Obesity, Physical Activity and Diet.

http://content.digital.nhs.uk/catalogue/PUB05131/obes-phys-acti-diet-eng-2012-rep .pdf

[2] National Institute for Health and Clinical Excellence (NICE) (2014) Obesity: Identification, Assessment and Management. (CG189). NICE, London.

http://www.nice.org.uk/guidance/cg189

[3] Sebire, N.J., Jolly, M., Harris, J.P., Wadsworth, J., Joffe, M., Beard, R.W., et al. (2001) Maternal Obesity and Pregnancy Outcome: A Study of 287,213 Pregnancies in London. International Journal of Obesity Related Metabolic Disorders, 25, 11751182. https://doi.org/10.1038/sj.ijo.0801670

[4] Rich-Edwards, J.W., Goldman, M.B., Willett, W.C., Hunter, D.J., Stampher, M.J., Colditz, G.A. and Manson, J.E. (1994) Adolescent Body Mass Index and Infertility Caused by Ovulatory Disorder. American Journal of Obstetrics and Gynecology, 171-177.

[5] Pattanayak, M., Ray, R. and Dutta, P. (2009) Impact of Lifestyle Modification in Obese Polycystic Ovary Syndrome. International Journal of Gynecology and Obstetrics, 107, 305.

[6] Johnson, N.P., Stewart, A.W., Falkiner, J., Farquhar, C.M., Milsom, S., Singh, V.-P., Okonkwo, Q.L. and Buckingham, K.L. (2010) PCOSMIC: A Multi-Centre Randomized Trial in Women with PolyCystic Ovary Syndrome Evaluating Metformin for Infertility with Clomiphene. Human Reproduction, 25, 1675-1683.

https://doi.org/10.1093/humrep/deq100

[7] Boots, C.E. and Stephenson, M.D. (2011) Does Obesity Increase the Rate of Miscarriage in Spontanous Conception: A Systematic Review. Seminars in Reproductive Medicine, 29, 507-513. https://doi.org/10.1055/s-0031-1293204

[8] Onofriescu, A., Nemescu, D., Onofriescu, M. and Vulopi, C. (2013) Clinical Outcome and Hormone Profile of Laparoscopic Ovarian Drilling in Women with Polycystic Ovarian Syndrome. Gynaecology, 9, 170-173.

[9] Souter, I., Baltagi, L.M., Kuleta, D., Meeker, J.D. and Petrozza, J.C. (2011) Women, Weight, and Fertility: The Effect of Body Mass Index on the Outcome of Superovulation/Intrauterine Insemination Cycles. Fertility \& Sterility, 95, 1042-1047.

[10] Li, H.W., Van Esch, M., De Vries, J., Duncan, W.C. and Anderson, R.A. (2010) Gonadotrophin Ovulation Induction Is a Successful Treatment for World Health Organisation Group II Anovulatory Subfertility in Women Aged up to 40 and with Body Mass Index up to 34. Human Fertility, 13, 35-40. 
https://doi.org/10.1055/s-0031-1293204

[11] Zander-Fox, D.L., Henshaw, R., Hamilton, H. and Lane, M. (2012) Does Obesity Really Matter? The Impact of BMI on Embryo Quality and Pregnancy Outcomes after IVF in Women Aged $\leq 38$ Years. Australian and New Zealand Journal of $\mathrm{Ob}$ stetrics and Gynaecology, 52, 270-276. https://doi.org/10.1111/j.1479-828X.2012.01453.x

[12] Misso, M.L., Costello, M.F., Garrubba, M., Wong, J., Hart, R., Rombauts, L., Melder, A.M., Norman, R.J. and Teede, H.J. (2013) Metformin versus Clomiphene Citrate for Infertility in Non-Obese Women with Polycystic Ovary Syndrome: A Systematic Review and Meta-Analysis. Human Reproduction Update, 19, 2-11. https://doi.org/10.1093/humupd/dms036

[13] Palomba, S., Falbo, A., Orio, F., Tolino, A. and Zullo, F. (2009) Efficacy Predictors for Metformin and Clomiphene Citrate Treatment in Anovulatory Infertile Patients with Polycystic Ovary Syndrome. Fertility \& Sterility, 91, 2557-2567.

[14] Lashen, H., Ledger, W., Lpoez Bernal, A. and Barlow, D. (1999) Extremes of Body Mass Do Not Adversely Affect the Outcome of Superovulation and in Vitro Fertilization. Human Reproduction, 14, 712-715.

[15] Maheshwari, A., Stofberg, L. and Bhattacharya, S. (2007) Effect of Overweight and Obesity on Assisted Reproductive Technology a Systematic Review. Human Reproduction Update, 13, 433-444. https://doi.org/10.1093/humupd/dmm017

[16] Metwally, M., Cutting, R., Tipton, A., Skull, J., Ledger, W.L. and Li, T.C. (2007) Effect of Increased Body Mass Index on Oocyte and Embryo Quality in IVF Patients. Reproductive Biomedicine Online, 15, 532-538.

[17] Rittenberg, V., Sobaleva, S., Ahmad, A., Oteng-ntim, E., Bolton, V., Khalaf, Y., Barude, P. and El-Toukhy, T. (2011) Influence of BMI on Risk of Miscarriage after Single Blastocyst Transfer. Human Reproduction, 26, 2642-2650. https://doi.org/10.1093/humrep/der254

[18] Farhi, J., Ben-Haroush, A., Sapir, O., Fisch, B. and Ashkenazi, J. (2010) High-Quality Embryos Retain Their Implantation Capability in Overweight Women. Reproductive Biomedicine Online, 21, 706-711.

[19] Dechaud, H., Anahory, T., Reyftmann, L., Loup, V., Hamamah, S. and Hedon, B. (2006) Obesity Does Not Adversely Affect Results in Patients Who Are Undergoing in Vitro Fertilization and Embryo Transfer. European Journal of Obstetrics Gynecology and Reproductive Biology, 127, 88-93.

[20] Esinler, I., Bozdag, G. and Yarali, H. (2008) Impact of Isolated Obesity on ICSI Outcome. Reproductive Biomedicine Online, 17, 583-587.

[21] Bellver, J., Ayllon, Y., Ferrando, M., Melo, M., Goyri, E., Pellicer, A., Remohi, J. and Meseguer, M. (2010) Female Obesity Impairs in Vitro Fertilization Outcome without Effecting Embryo Quality. Fertility Sterility, 93, 447-454.

[22] Sathya, A., Balasubramanyam, S., Gupta, S. and Verma, T. (2010) Effect of Body Mass Index on in Vitro Fertilization Outcomes in Women. Journal of Human Reproductive Sciences, 3, 135-138. https://doi.org/10.4103/0974-1208.74155

[23] Zhang, D., Zhu, Y., Gao, H., Zhou, B., Zhang, R., Wang, T., Ding, G., Qu, F., Haung, H. and Lu, X. (2010) Overweight and Obesity Negatively Affect the Outcomes of Ovarian Stimulation and in Vitro Fertilisation: A Cohort Study of 2628 Chinese Women. Gynecological Endocrinology, 26, 325-332. https://doi.org/10.3109/09513591003632100

[24] Thakur, M., Imudia, A.N., Shavell, V.I., Singh, M., Diamond, M.P. and Awonuga, A.O. (2012) Should Body Mass Index Influence the Dose of hCG for Ovulation In- 
duction after Superovulation in IVF/ICSI Cycles? Fertility and Sterility, 98, S271S272.

[25] Kavrut, M. and Kahrama, S. (2013) Comparison of Two Doses of Recombinant HCG for Oocyte Maturation in Obese Women (BMI > or $=30$ ) Undergoing Assisted Reproductive Techniques. Ginekologia Polska, 84, 603-608.

[26] Kolibianakis, E., Zikopoulos, K., Albano, C., Camus, M., Tournaye, H., Van Steirteghem, A. and Devroey, P. (2008) Reproductive Outcome of Polycystic Ovarian Syndrome Patients Treated with GnRH Antagonists and Recombinant FSH for IVF/ICSI. Reproductive BioMedicine Online, 7, 313-318.

[27] Bailey, A.P., Hawkins, L.K., Missmer, S.A., Correia, K.F. and Yanushpolsky, E.H. (2014) Effect of Body Mass Index on in Vitro Fertilization Outcomes in Women with Polycystic Ovary Syndrome. American Journal of Obstetrics and Gynecology, 211, 163.e1-6.

[28] Rabinson, J., Meltcer, S., Zohav, E., Gemer, O., Anteby, E.Y. and Orvieto, R. (2008) GnRH Agonist versus GnRH Antagonist in Ovarian Stimulation: The Influence of Body Mass Index on in Vitro Fertilization Outcome. Fertility and Sterility, 89, 472474.

[29] Pandey, S., McLernon, D.J., Scotland, G., Mollison, J., Wordsworth, S. and Bhattacharya, S. (2014) Cost of Fertility Treatment and Live Birth Outcome in Women of Different Ages and BMI. Human Reproduction, 29, 2199-2211. https://doi.org/10.1093/humrep/deu184

[30] Brewer, C.J. and Balen, A.H. (2010) Focus on Obesity: The Adverse Effects of Obesity on Conception and Implantation. Reproduction, 140, 347-364. https://doi.org/10.1530/REP-09-0568

[31] Machtinger, R., Combelles, C.M.H., Missmer, S.A., Correia, K.F., Fox, J.H. and Racowsky, C. (2012) The Association between Severe Obesity and Characteristics of Failed Fertilized Oocytes. Human Reproduction, 27, 3198-3207. https://doi.org/10.1093/humrep/des308

[32] Cohen, J. (1996) Laparoscopic Procedures for Treatment of Infertility Related to Polycystic Ovarian Syndrome. Human Reproduction Update, 2, 337-344. https://doi.org/10.1093/humupd/2.4.337

[33] Wu, M.H., Huang, M.F., Tsai, S.J., Pan, H.A., Cheng, Y.C. and Lin, Y.S. (2004) Effects of Laparoscopic Ovarian Drilling on Young Adult Women with Polycystic Ovarian Syndrome. Journal of the American Association of Gynecologic Laparoscopists, 11, 184-190.

[34] Gomel, V. and Yarali, H. (2004) Surgical Treatment of Polycystic Ovary Syndrome Associated with Infertility. Reproductive BioMedicine Online, 9, 35-42.

[35] Malkawi, H.Y. and Qublan, H.S. (2005) Laparoscopic Ovarian Drilling in the Treatment of Polycystic Ovary Syndrome: How Many Punctures per Ovary Are Needed to Improve the Reproductive Outcome? Journal of Obstetrics and Gynaecology Research, 31, 115-119. https://doi.org/10.1111/j.1447-0756.2005.00255.x

[36] Lutsiv, O., Mah, J., Beyene, J. and McDonald, S.D. (2015) The Effects of Morbid Obesity on Maternal and Neonatal Health Outcomes: A Systematic Review and Meta-Analyses. Obesity Reviews, 16, 531-546. https://doi.org/10.1111/obr.12283

[37] Balen, A., Platteau, P., Andersen, A., Devroey, P., Sørensen, P., Helmgaard, L. and Arce, J.C. (2006) The Influence of Body Weight on Response to Ovulation Induction with Gonadotrophins in 335 Women with World Health Organization Group II Anovulatory Infertility. BJOG: An International Journal of Obstetrics \& Gynaecology, 113, 1195-1202. https://doi.org/10.1111/j.1471-0528.2006.01034.x 
Submit or recommend next manuscript to SCIRP and we will provide best service for you:

Accepting pre-submission inquiries through Email, Facebook, LinkedIn, Twitter, etc. A wide selection of journals (inclusive of 9 subjects, more than 200 journals)

Providing 24-hour high-quality service

User-friendly online submission system

Fair and swift peer-review system

Efficient typesetting and proofreading procedure

Display of the result of downloads and visits, as well as the number of cited articles Maximum dissemination of your research work

Submit your manuscript at: http://papersubmission.scirp.org/

Or contact ojog@scirp.org 